\title{
Prevalence of ventricular preexcitation in Japanese schoolchildren
}

\author{
S Sano, S Komori, T Amano, I Kohno, T Ishihara, T Sawanobori, H Ijiri, K Tamura
}

\begin{abstract}
Background-Wolff-Parkinson-White syndrome is thought to be a congenital disease, however, its exact prevalence is not known. This may be because of the intermittent activity of accessory pathways in some cases and fluctuations in autonomic tone. Aims-To investigate the prevalence of ventricular preexcitation by electrocardiography and reported symptoms in each school age child in Yamanashi prefecture. Methods-From 1994 to 1996 , answers to a questionnaire, results of physical examination, and electrocardiography were obtained from all schoolchildren in Yamanashi prefecture ( $n=92161$; total population 880 000) on admission to elementary school (age 6 to 7 years, n = 28 395), junior high school (age 12 to 13 years, $n=31206)$, and high school (age 14 to 15 years, $n=32837$ ).

Results-Elementary and junior high school students had a significantly lower prevalence of preexcitation than high school students $(0.073 \%$ and $0.070 \% v$ $0.174 \%, p<0.001)$. The prevalence of left free wall pathway was highest in high school students $(n=27)$ compared with elementary $(n=6)$ and junior high school students $(n=5) \quad(p<0.005)$. The only symptom noted in the answers to the questionnaire was palpitations. The symptomatic cases were more frequent in high school $(n=13)$ than in elementary $(n=1)$ and junior high school $(n=2)$ children, but not significantly. No student with preexcitation had associated heart disease or family history of WolffParkinson-White syndrome or sudden death.
\end{abstract}

Conclusions-The prevalence of preexcitation in younger schoolchildren was less frequent than previously reported. The prevalence of preexcitation and left free wall pathways increased with age. The symptoms were few and there was no significant morbidity.

(Heart 1998;79:374-378)

Keywords: preexcitation; Wolff-Parkinson-White syndrome; children; epidemiology

Wolff-Parkinson-White (WPW) syndrome can be caused by the existence of accessory pathways that can be associated with congenital heart defects. Occasionally, preexcitation phenomena detected by a surface electrocardiogram will disappear with age. This may be explained by normal development in babies and by myocardial degeneration in adults. ${ }^{1-5}$ Although intermittent WPW syndrome is not rare, ${ }^{6-12}$ its exact prevalence is not known. There have been few population based studies of WPW syndrome, especially in children. We designed an investigation of the changes of ventricular preexcitation during growth in conjunction with routine school medical examinations.

\section{Methods}

The answers to a questionnaire, the results of physical examination, and electrocardiography were obtained from all schoolchildren in Yamanashi prefecture as required by law, when they entered elementary school, junior high school, or high school. These data were reviewed by the heart examination judgment committee of the medical association in Yamanashi prefecture. The committee comprises 15 physicians in the fields of cardiology and paediatrics. In the questionnaire, students were asked about past history of heart disease, family history, and symptoms of palpitations or syncope (table 1). The questionnaires were answered at home by parents or guardians. The 12 lead electrocardiograms were analysed by computer and reviewed by a member of the heart examination judgment committee. A diagnosis of ventricular preexcitation was made by following criteria: PR interval $<0.12 \mathrm{sec}-$ onds, $0^{\circ}<\mathrm{P}$ axis $\leqslant 90^{\circ}$, and the presence of a delta wave. Children diagnosed with ventricular preexcitation underwent the second medical examination and received guidance of management from a cardiologist or paediatrician. The second examination was left entirely to the child's practitioner's judgment.

Copies of the answers to the questionnaire, the electrocardiograms, and the guidance were reviewed by the heart examination judgment committee. Two cardiologists re-analysed these electrocardiograms independently, and the location of the accessory pathway was determined by agreement between two evaluators. We divided the location of the accessory pathways into four categories: right free wall, septal wall, left free wall, and unknown. ${ }^{13-16}$ It is thought that this classification may provide useful and prognostic information, as right sided WPW syndrome frequently is associated with heart disease in infants and children with supraventricular tachycardia. ${ }^{8}$ We diagnosed the apparent location of accessory pathways according to Reddy's criteria. ${ }^{15}$ These criteria are based on adult surface electrocardiograms and take account of both polarity of delta waves and vector of QRS complex. In cases where the QRS morphology was not fully preexcited, we
409-38, Japan.

Accepted for publication 14 November 1997 


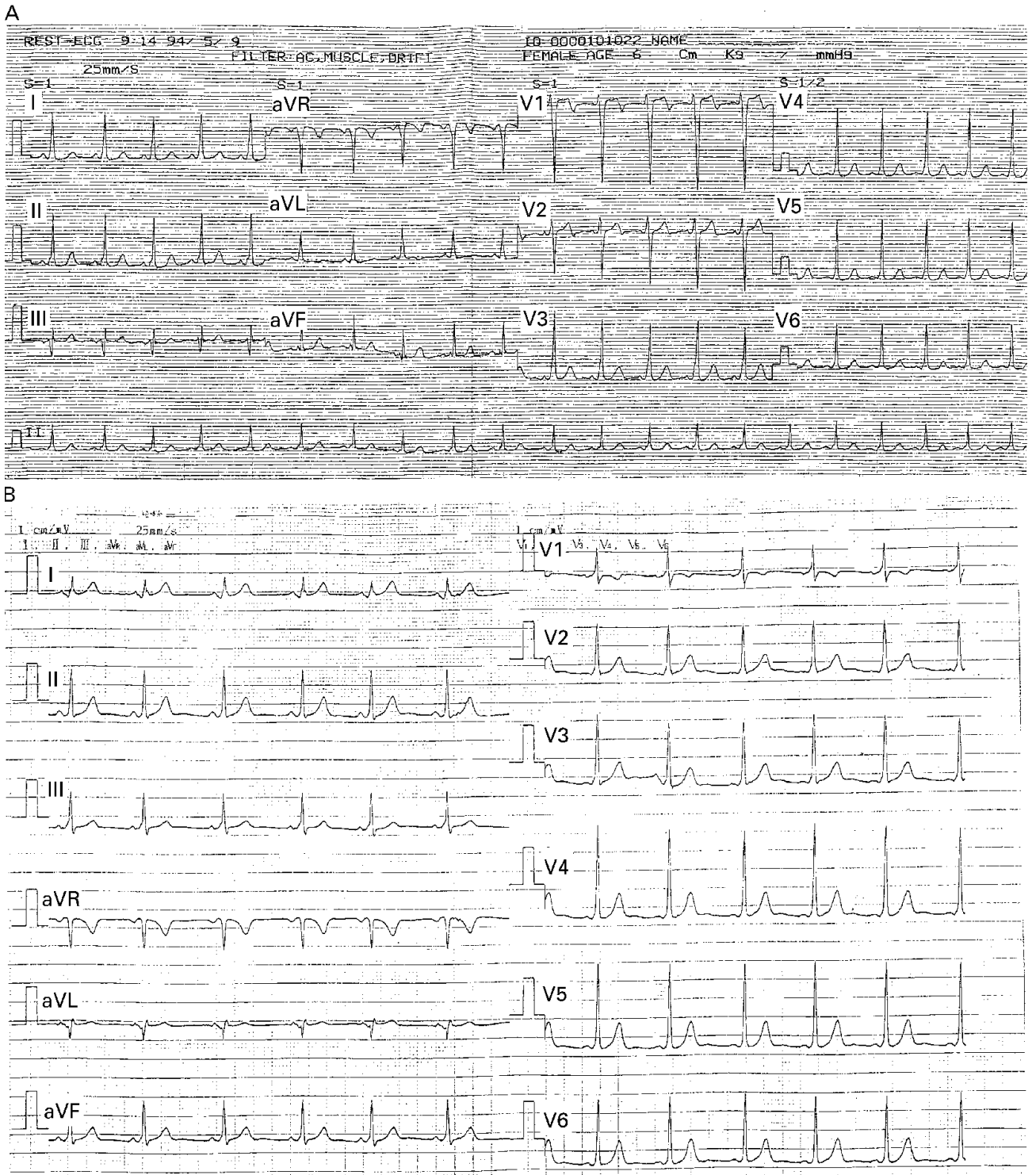

Figure 1 Examples of the electrocardiograms. (A) The accessory pathway probably exists in the right lateral free wall. (B) The accessory pathway probably exists in the left lateral to left anterolateral free wall.

determined the location of the accessory pathway mainly dependent on polarity of the delta waves. We examined the prevalence, the apparent location of accessory pathways, the male to female ratio, and subjective symptoms of ventricular preexcitation in the children.

STATISTICS

Fisher's exact probability test was used for the male to female ratio and presence of symptoms. The $\chi^{2}$ test was used for prevalence.

Table 1 Questionnaire completed by parents of all children in Yamanashi prefecture as they entered school

Have you ever been diagnosed with any heart disease? How old were you when it was first diagnosed?

What disease(s) have you been diagnosed with?

What management have you received?

Have you ever had diseases such as chorea, rheumatic fever, Kawasaki disease, hypertension, sepsis, thyroid disease, arthritis?

Have you had any of the following symptoms: fatigue, palpitations, shortness of breath, chest pressure, syncope or faintness?

Do you have any blood relatives who had sudden death younger than 40 years old?

\section{Results}

Figure 1 shows two sample electrocardiograms. In fig $1 \mathrm{~A}$, the $\mathrm{R}: \mathrm{S}$ ratio in lead $\mathrm{V} 1$ is $<1$ and the delta wave is positive in lead I, indicating that the accessory pathway exists in the right lateral free wall. In fig $1 \mathrm{~B}$, where the R:S ratio in $\mathrm{V} 1$ is $>1$, and the delta wave is positive in aVF, the accessory pathway exists in the left lateral to left anterolateral free wall.

In total, 92161 students underwent examinations on admission to school. All children registered underwent routine school medical examination as required by law. The compliance of screened children was almost $100 \%$. One hundred students were diagnosed with ventricular preexcitation, and 99 underwent the second medical examination. One high school student was absent from school for a long time and did not undergo the second heart examination. Two cardiologists reanalysed 99 electrocardiograms and in two of them there were neither obvious delta waves 
Table 2 Prevalence and location of accessory pathways in fapanese schoolchildren

\begin{tabular}{llllllll}
\hline & & \multicolumn{7}{c}{ Location } & & Male/ \\
\cline { 3 - 6 } & Symptoms & Prevalence & Left & Right & Septal & Unknown & female \\
\hline $\begin{array}{c}\text { Elementary } \\
\text { school }\end{array}$ & $1(4.8 \%)$ & $\begin{array}{l}21 / 28395 \\
(0.073 \%)\end{array}$ & 6 & 10 & 5 & 0 & $9 / 12$ \\
$\begin{array}{c}\text { Junior high } \\
\text { school }\end{array}$ & $2(9.1 \%)$ & $\begin{array}{l}22 / 31206 \\
(0.070 \%)\end{array}$ & 5 & 12 & 5 & 0 & $11 / 11$ \\
High school & $13(22.8 \%)$ & $\begin{array}{l}57 / 32837 \\
(0.174 \%)^{\star}\end{array}$ & $27 \dagger$ & 15 & 12 & 3 & $32 / 25$ \\
Total & $16(16.0 \%)$ & $\begin{array}{l}100 / 92161 \\
(0.109 \%)\end{array}$ & 40 & 37 & 22 & 3 & $52 / 48$ \\
& & & & & &
\end{tabular}

High school students had a significantly higher prevalence of ventricular preexcitation and left free wall pathways than elementary and junior high school students.

${ }^{\star} \mathrm{p}=0.00086 v$ elementary school and $\mathrm{p}=0.00032 v$ junior high school; $\mathrm{tp}=0.0021 v$ elementary school and $\mathrm{p}=0.00036 v$ junior high school.

Symptoms, prevalence of symptomatic children with ventricular preexcitation.

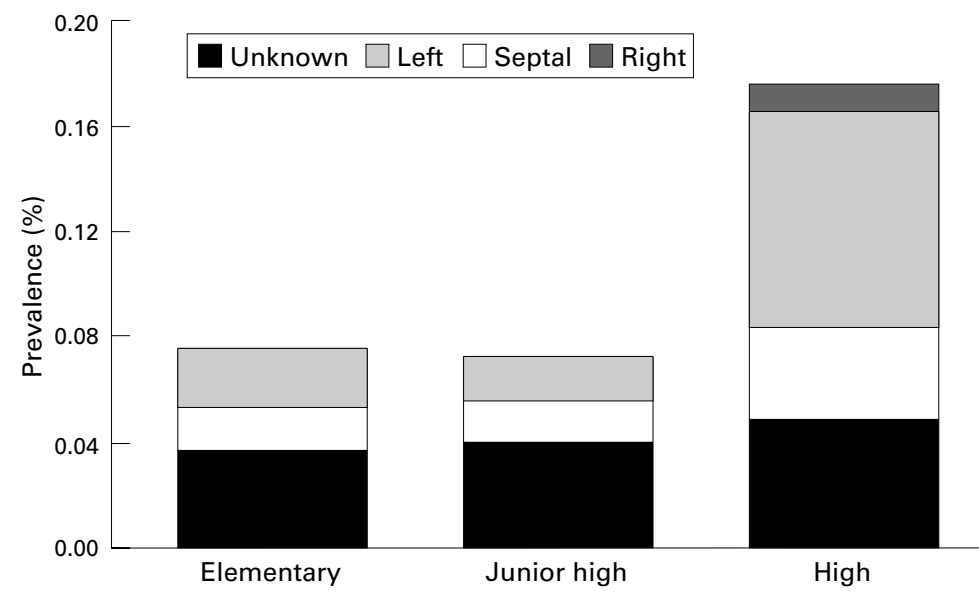

Figure 2 Prevalence of ventricular preexcitation in schoolchildren. High school students have significantly higher prevalence of ventricular preexcitation and left free wall pathway than elementary and junior high school students. Prevalence of ventricular preexcitation: $p=0.00086 v$ elementary school; $p=0.00036 v$ junior high school. Prevalence of left free wall accessory pathway: $p=0.0021 v$ elementary school; $p=0.00032 v$ junior high school. Prevalence of ventricular preexcitation in elementary $v$ junior high school was not significant.

nor short PR intervals. These two schoolchildren previously had been diagnosed as having preexcitation syndrome. We regarded them as having an intermittent syndrome.

We divided the children into three groups: elementary school (age 6 to 7 years, $\mathrm{n}=28395$ ), junior high school (age 12 to 13 years, $n=31206$ ), and high school (age 15 to 16 years, $n=32837$ ). The prevalence of ventricular preexcitation in the three groups was $0.073 \%, 0.070 \%$, and $0.174 \%$, respectively, and $0.109 \%$ in all schoolchildren (table 2 ). The diagnosis by the computer algorithms included 53 cases of WPW syndrome pattern, 12 of intraventricular conduction delay, eight of abnormal Q wave, seven of bundle branch block, three of ST-T abnormality, and one of left ventricular hypertrophy. Twenty one cases were judged as within normal limits by the computer algorithms. Therefore, the pure sensitivity of the computer diagnosis for ventricular preexcitation was $47.4 \%$. Because each computer was not connected online and we could not take statistics of the computer diagnosis of all the schoolchildren, the specificity was not known.

High school students had a significantly higher prevalence of preexcitation than elementary $(p=0.0086)$ and junior high school students $(p=0.00032)$. The ratio of boys to girls was almost $1: 1$ in all schoolchildren and there was no significant difference between each grade, however, the proportion of boys increased in older schoolchildren.

Prevalence of left free wall pathways in high school students was significantly higher than in elementary $(p=0.0021)$ and junior high school students $(p=0.00036)$, but there was no significant difference in right free wall and septal wall pathways (fig 2).

Three high school students had an accessory pathway of unknown location; two were thought to have intermittent disease. They previously had been diagnosed as having ventricular preexcitation, but no delta wave was recognised at the time of our assessment.

The only symptoms were palpitations. The schoolchildren with ventricular preexcitation never complained of syncope. The frequency of symptoms was higher in high school students but this was not significant. To our knowledge, two symptomatic high school students underwent invasive electrophysiological study and one of them had catheter ablation of the left accessory pathway because of frequent supraventricular tachycardia and atrial fibrillation.

None of the children with ventricular preexcitation had associated heart disease or a family history of WPW syndrome or sudden death.

\section{Discussion}

PRINCIPAL FINDINGS

The prevalence of ventricular preexcitation in Japanese schoolchildren was different among various age groups. The lowest prevalence of preexcitation was in the youngest children. Left free wall accessory pathways were more commonly diagnosed by electrocardiography in older children. Symptoms were few and there was no significant morbidity.

COMPARISON WITH PREVIOUS STUDIES

The overall prevalence of ventricular preexcitation has been reported to be $0.15 \%$ to $0.4 \%$. The male:female ratio is roughly $2: 1 .^{6-9}{ }^{15}{ }^{16} \mathrm{It}$ is also known that the delta wave may disappear during the natural course of WPW syndrome for the following reasons: normal maturation of the atrioventricular node; disappearance of defects in the annulus fibrosis with growth; variation in the autonomic nervous system during infancy; and reduction of conductivity owing to myocardial degeneration with aging in adult life. ${ }^{12}$ Klein et al reported that among 29 adult patients with the WPW electrocardiographic pattern, nine $(31 \%)$ patients lost the pattern during two electrophysiological studies a mean (SD) of 54.7 (14) months apart. ${ }^{1}$ Moreover, intermittent WPW syndrome is common, so the exact prevalence of this syndrome is not known.

Some Japanese investigators have reported that the frequency of WPW syndrome increases with age in Japanese children. ${ }^{17}{ }^{18}$ However, there are no other reports in the English language literature describing this phenomenon.

In adults, left free wall accessory pathway has been reported to be the most common (40-50\%), followed by posteroseptal (20- 
$30 \%$ ), right free wall (10-20\%), and anteroseptal $(2-9 \%)$ locations. ${ }^{6} 1316$ However, in children, right sided pathways have been reported to be slightly more common than in adults. ${ }^{910}$ There are no data on how the location of accessory pathways change with age.

The pathophysiological explanation of our findings is as follows. The prevalence of ventricular preexcitation is underestimated, as an intermittent type of WPW syndrome is common $^{121112}$ and latency of the delta wave may occur because of changes in autonomic nervous tone. It is known that the delta wave may disappear in the natural course of WPW syndrome. ${ }^{1{ }^{34}}$ In our study, the prevalence of left accessory pathways in elementary and junior high school students was lower than in previous reports. Furthermore, our data showed equivalent prevalence in high school students compared with reported data in adults. Therefore, based on our data it could be presumed that the higher prevalence of ventricular preexcitation may be attributable to the manifestation of left free wall accessory pathways with growth. As the left free wall accessory pathway is located further from the sinus node than the right and septal pathways, the sensitivity of the surface electrocardiogram may be limited. ${ }^{14}$ It also has been reported that a left sided accessory pathway is more frequent in intermittent WPW syndrome, ${ }^{19} 20$ and that such a pathway may manifest itself in response to changes in autonomic nervous tone and atrioventricular (AV) nodal conductivity that occur during growth. ${ }^{14}$ We could not explain the reason for the difference in the male to female ratio between present and previous reports. However, the ratio of male to female was $>1$ in older schoolchildren.

We did not find a significant difference, however the frequency of cardiac symptoms increased with age. Several mechanisms may explain this. For instance, anatomic, autonomic, hormonal, or emotional changes during adolescence may play a role. In addition, normal maturation of the conduction system and changes in autonomic tone result in modifications of the refractory periods of the AV node and accessory pathways. ${ }^{21} 22$ Consequently, a reentrant circuit can be formed. It is known that changes in the levels of sex hormones can vary adrenergic sensitivity, ${ }^{22} 23$ and that emotional instability stimulates the sympathetic nervous system. ${ }^{21}$

Our data relied heavily on the answers to the questionnaire. Younger children may not be able to articulate clearly their symptoms, and their parents may overlook them. Therefore, we may have underestimated the prevalence of symptoms, especially in younger children. Furthermore, we have no data directly associating the palpitations with arrhythmia.

Perry and Garson ${ }^{5}$ have reported that $93 \%$ of infants who have supraventricular tachycardia as newborns will stop having episodes of tachycardia by 8 months old, but $31 \%$ will relapse at a mean age of 8 years. Their study patients, however, were hospital based. In the present study, there was only one child who had been diagnosed with ventricular preexcitation as a newborn, and no other children had a history of symptoms in the neonatal period. This difference may be due to the fact that such a diagnosis was based on the answers to the questionnaire, subject to incomplete recall by parents.

\section{LIMITATIONS}

Our study was based on the results of the school examinations from 1994 to 1996 only and does not truly address change with growth. The study was performed as a cross sectional study, although this kind of problem should ideally be assessed by a longitudinal approach. Further prospective and longitudinal studies are underway in our group at this time, so that new data should be available in the near future. In addition, we determined the prevalence of ventricular preexcitation and the location of accessory pathways with a single electrocardiogram that could not always be preexcited at maximum. Trivial delta waves may be missed, especially in children where rapid AV node conduction may mask preexcitation. This may account for the lower than expected incidence of ventricular preexcitation in younger schoolchildren. Furthermore, we used Reddy's criteria, which are applicable only to adults. Only two schoolchildren with preexcited electrocardiograms underwent electrophysiological study, so we could not determine the exact location of the accessory pathways.

Familial clustering has been documented in WPW syndrome, ${ }^{24}$ but there was no evidence of this in our study. This may depend on the incomplete information regarding pedigrees because of the difficulty of documenting diagnoses in the past. We assessed family history only by a questionnaire and this approach should be revised in future studies.

There were no children diagnosed with associated heart disease. This may be attributed to omission of echocardiograms in the second medical examination. Because many schoolchildren underwent the second examination at their practitioner's office, echocardiography might be omitted.

\section{CLINICAL IMPLICATIONS}

Ventricular preexcitation in younger schoolchildren is less frequent than previously reported in adult populations, the symptoms are fewer without significant morbidity, and the presence of ventricular preexcitation on the electrocardiogram increases with age. A single electrocardiogram during elementary school may not predict the development of WPW syndrome and exclude the diagnosis in later life. Therefore, longitudinal and chronological follow up studies of electrocardiograms from early life are important for both diagnosis and prognosis.

1 Klein GJ, Yee R, Sharma AD. Longitudinal electrophysiologic assessment of asymptomatic patients with WolffParkinson-White electrocardiographic pattern. $N$ Engl $f$ Med 1989;320:1229-33.

2 Krahn AD, Manfreda J, Robert B, et al. The natural history of electrocardiographic preexcitation in men: the Manitoba follow-up study. Ann Intern Med 1992;116:456-60.

3 Wolff GS, Han J, Curran J. Wolff-Parkinson-White syndrome in the neonate. Am f Cardiol 1978;41:559-63. 
4 Klein GJ, Hackel DB, Gallagher JJ. Anatomic substrate of impaired antegrade conduction over an accessory atrioventricular pathway in the Wolfte
Circulation $1980 ; 61: 1249-56$.

5 Perry JC, Garson A Jr. Supraventricular tachycardia due to Wolff-Parkinson-White syndrome in children: early disappearance and late recurrence. $\mathcal{F}$ Am Coll Cardiol 1990;16: 1215-20.

6 Munger TM, Packer DL, Hammill SC, et al. A population study of the natural history of Wolff-Parkinson-White syndrome in Olmsted Country, Minnesota, 1953-1989. Circulation 1993;87:866-73.

7 Giardina ACV, Ehlers KH, Engle MA. Wolff-ParkinsonWhite syndrome in infants and children. A long-term follow-up study. Br Heart f 1972;34:839-46.

8 Deal BJ, Keane JF, Gillette PC, et al. Wolff-Parkinson-White syndrome and supraventricular tachycardia during infancy: management and follow-up. $\mathcal{f}$ Am Coll Cardiol 1985;5:1305 .

9 Mantakas ME, Mccue CM, Miller WW. Natural history of Wolff-Parkinson-White syndrome discovered in infancy. Wolff-Parkinson-White syndrom

10 Gillette PC, Garson A Jr, Kugler JD. Wolff-Parkinson-White syndrome in children: electrophysiologic and pharmacologic characteristics. Circulation 1979;60:1487-95.

11 Berkman NL, Lamb LE. The Wolff-Parkinson-White electrocardiogram, a follow-up study of five to twenty-eight years. N Engl F Med 1968;278:474-8.

12 Klein GJ, Gulamhusein SS. Intermittent preexcitation in the Wolff-Parkinson-White syndrome. Am f Cardiol 1983, 52:292-6.

13 Gallagher JJ, Sealy WC, Cox JL, et al. Results of surgery for preexcitation caused by accessory atrioventricular pathways in 267 consecutive cases. In: Josephson ME, Wellens HJJ, eds. Tachycardias: mechanisms, diagnosis, treatment Philadelphia: Lea \& Febiger, 1984:259-69.
14 Willems JL, Robles de Medina EO, Bernard R, et al. Criteria for intraventricular conduction disturbances and preexcitation. $f$ Am Coll Cardiol 1985;5:1261-75.

15 Reddy GV, Schamroth L. The localization of bypass tracts in the Wolff-Parkinson-White syndrome from the surface electrocardiogram. Am Heart f 1987;113:984-93.

16 Zipes DP. Specific arrythmias. diagnosis and treatment. In: Brawnwald E, ed. Heart disease. A textbook of cardiovascular medicine

17 Ohkuni M. Management of arrhythmias in schoolchildren [in Japanese]. Fournal of the Fapan Medical Association 1995; 114:1381-5.

18 Tsuda J. Statistics of heart and renal disease in school age. Health guidance of heart and renal disease in childhood [in Japanese]. Tokyo: Kyorinshoin, 1979:3-11.

19 Sung RJ. Clinical and electrophysiologic observations in patients with concealed accessory atrioventricular bypass tracts. Am f Cardiol 1977;40:839-47.

20 Gillette PC. Concealed anomalous cardiac conduction pathways: a frequent cause of supraventricular tachycardia. Am f Cardiol 1977;40:848-52.

21 Schwartz PJ, Priori SG Sympathetic nervous system and cardiac arrhythmias. In: Zipes DP, Jalife J, eds. Cardiac electrophysiology: from cell to bedside. Philadelphia: WB Saunelectrophysiology: from

22 Widerhorn J, Widerhorn ALM, Rahimtoola SH, et al. WPW syndrome during pregnancy: increased incidence of supraventricular arrhythmias. Am Heart f 1992;123:796-8.

23 Roberts JM, Insel PA, Goldfien A. Regulation of myometrial adrenoreceptors and adrenergic response by sex steroids. Mol Pharmacol 1981;20:52-8.

24 Vidallet HJ Jr, Pressley JC, Henke E, et al. Familial occurrence of accessory atrioventricular pathways. $\mathrm{N} \mathrm{Englf}$ Med 1987;317:65-9. 